\title{
Natural occurrence of microcystin synthetase deletion mutants capable of producing microcystins in strains of the genus Anabaena (Cyanobacteria)
}

\begin{abstract}
Correspondence
Kaarina Sivonen

kaarina.sivonen@helsinki.fi
\end{abstract}

Received 18 December 2007

Revised 4 February 2008

Accepted 4 February 2008
David P. Fewer, ${ }^{1}$ Ave Tooming-Klunderud, ${ }^{2}$ Jouni Jokela, ${ }^{1}$ Matti Wahlsten, ${ }^{1}$ Leo Rouhiainen, ${ }^{1}$ Tom Kristensen, ${ }^{2}$ Thomas Rohrlack, ${ }^{3}$ Kjetill S. Jakobsen ${ }^{4}$ and Kaarina Sivonen ${ }^{1}$

\author{
${ }^{1}$ Department of Applied Chemistry and Microbiology, PO Box 56, Viikki Biocenter, Viikinkaari 9, \\ FIN-00014, University of Helsinki, Finland \\ ${ }^{2}$ Institute of Molecular Biosciences, PO Box 1041, Blindern, University of Oslo, Norway \\ ${ }^{3}$ NIVA - Norwegian Institute for Water Research, 0441 Oslo, Norway \\ ${ }^{4}$ Centre for Ecological and Evolutionary Synthesis, Department of Biology, University of Oslo, \\ Norway
}

\begin{abstract}
Microcystins form a large family of small cyclic heptapeptides harbouring extensive modifications in amino acid residue composition and functional group chemistry. These peptide hepatotoxins contain a range of non-proteinogenic amino acids and unusual peptide bonds, and are typically $N$-methylated. They are synthesized on large enzyme complexes consisting of non-ribosomal peptide synthetases and polyketide synthases in a variety of distantly related cyanobacterial genera. Here we report a $1236 \mathrm{bp}$ in-frame deletion mutation in the $m c y A$ gene of the microcystin biosynthetic pathway in nine strains of the genus Anabaena. The deletion removed almost the entire $N$-methyltransferase (NMT) domain. Strains of Anabaena carrying the in-frame deletion mutation incorporated mainly dehydroalanine (Dha) into the microcystins they produce while strains with full-length mcyA genes incorporated mainly $N$-methyldehydroalanine (Mdha). Interestingly, the strains of Anabaena lacking the NMT domain also incorporated elevated amounts of L-Ser, the precursor of Mdha and Dha, into the microcystin they produced relative to strains carrying functional NMT domains. We provide evidence for the in-frame deletion of the NMT domain without the co-conversion of the flanking adenylation domain. Our results demonstrate a further example of the strategies employed by cyanobacteria in the biosynthesis of microcystin variants.
\end{abstract}

\section{INTRODUCTION}

Anabaena is a common component of freshwater phytoplankton worldwide and strains of this genus produce a wide range of bioactive compounds, including neurotoxins and hepatotoxins (Sivonen \& Jones, 1999). These cyanobacteria form filaments and contain gas vesicles allowing them to float to the surface during periods of calm weather to form thick surface scums (Stal et al., 2003). Microcystinproducing strains of the genus Anabaena have been reported from Canada, Finland, France, Norway and Denmark (Sivonen \& Jones, 1999). Anabaena is also

Abbreviations: Dha, dehydroalanine; Mdha, N-methyldehydroalanine; NMT, N-methyltransferase; SAM, S-adenosylmethionine.

A supplementary table with details of the microcystin variants produced by the 26 strains of Anabaena studied is available with the online version of this paper. common in brackish-water environments and contributes to bloom formation each summer in the Baltic Sea (Karlsson et al., 2005; Stal et al., 2003). These blooms are amongst the largest mass occurrences of cyanobacteria in the world (Kahru, 1997) and have recently been demonstrated to contain microcystin-producing Anabaena (Halinen et al., 2007).

Microcystins are implicated in the toxicosis of wild and domestic animals worldwide (Ressom et al., 1994). They are potent inhibitors of eukaryotic protein phosphatases 1 and 2A (MacKintosh et al., 1990). These toxins penetrate the liver cell membranes via the bile acid route and lead to overphosphorylation and disruption of the cytoskeleton in hepatocytes (Carmichael, 1994). They cause hepatocyte necrosis, leading to pooling of blood in the liver. In acute poisoning, death is the result of intrahepatic haemorrhage and hypovolemic shock (Carmichael, 1994). Microcystins 
are also suspected to be tumour promoters (NishiwakiMatsushima et al., 1992), and the use of water contaminated with the toxin in renal dialysis was held responsible for the deaths of 60 patients in Brazil (Jochimsen et al., 1998). The World Health Organization has set a provisional guideline of $1 \mu \mathrm{g}$ microcystin-LR per litre of drinking water (WHO, 1998).

Microcystins are small cyclic heptapeptides with an unusual chemical structure and a number of nonproteinogenic amino acids (Sivonen \& Jones, 1999). They share the common structure cyclo-D-Ala ${ }^{1}-\mathrm{X}^{2}-\mathrm{D}-\mathrm{MeAsp}{ }^{3}-$ $\mathrm{Z}^{4}$-Adda ${ }^{5}$-D-Glu ${ }^{6}-\mathrm{Mdha}^{7}$ where D-MeAsp is D-erythro- $\beta$ methylaspartic acid, Adda is (2S,3S,8S,9S)-3-amino-9methoxy-2,6,8-trimethyl-10-phenyl-(4E),(6E)-decadienoic acid, D-Glu is D-iso-glutamic acid, and $\mathrm{X}$ and $\mathrm{Z}$ are variable L-amino acids (Fig. 1). Microcystins typically contain three variable methyl groups, including $\mathrm{N}$-methyl, $\mathrm{O}$-methyl and $C$-methyl groups (Fig. 1). Methylation is a relatively common modification in biologically active natural peptides and is thought to improve stability against proteolytic degradation (Finking \& Marahiel, 2004; Sieber \& Marahiel, 2005).

Microcystins are synthesized by a thiotemplate mechanism on large synthetases in a programmed biosynthetic event (Dittmann et al., 1997). In Anabaena this enzyme complex is encoded in a $55 \mathrm{~kb}$ gene cluster containing 10 genes (mcyA$J$ ) encoding peptide synthetases, polyketide synthases and tailoring enzymes (Rouhiainen et al., 2004). Non-ribosomal peptide synthetases possess a highly conserved modular structure with each module consisting of catalytic domains responsible for the adenylation, thioester formation and condensation of specific amino acids (Marahiel et al., 1997). The arrangement of these domains within the multifunctional enzymes determines the number and order of the amino acid constituents of the peptide product (Sieber \&

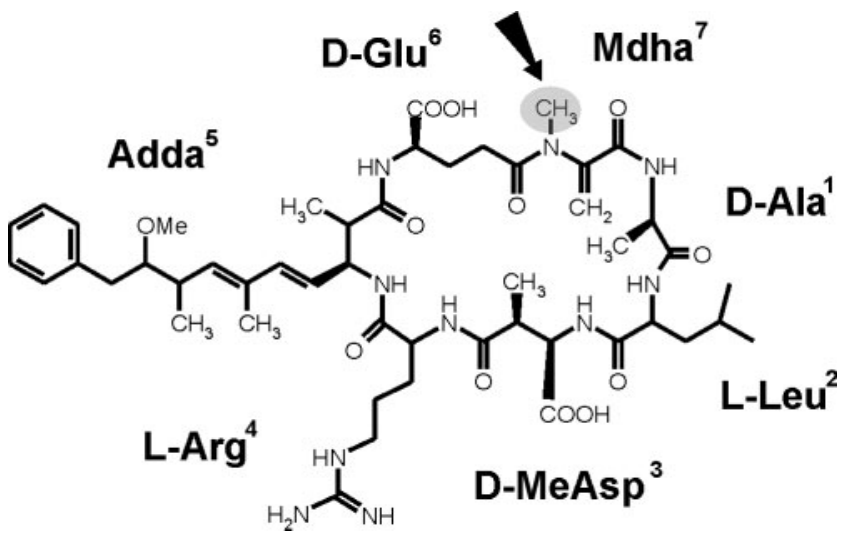

Fig. 1. The microcystin chemical structure can be generalized as cyclo-D-Ala ${ }^{1}-X^{2}-D-M e A s P^{3}-Z^{4}-A_{d d a}{ }^{5}-D-G l u^{6}-M_{d h a}{ }^{7}$, where $X$ and $Z$ denote the highly variable $L$-amino acids present at the second and fourth positions. The arrow indicates the $N$-methyl group of Mdha.
Marahiel, 2005). Additional domains for the modification of amino acid residues such as epimerization, heterocyclization, oxidation, formylation, reduction or $\mathrm{N}$-methylation may also be included in the module (Lautru \& Challis, 2004; Marahiel et al., 1997; Sieber \& Marahiel, 2005). Microcystins typically contain the unusual non-proteinogenic amino acid $\mathrm{N}$ methyldehydroalanine (Mdha) (Fig. 1). N-Methylation of the microcystins is achieved by the $N$-methyltransferase (NMT) domain in the first module of McyA (Nishizawa et al., 1999; Tillett et al., 2000; Christiansen et al., 2003; Rouhiainen et al., 2004). The NMT domain catalyses the transfer of the $S$-methyl group from $S$-adenosylmethionine (SAM) to the $\alpha$-amino group of the thioesterified amino acid (Sieber \& Marahiel, 2005).

The strategies employed by microcystin-producing cyanobacteria to achieve chemical variation in amino acid residue composition and functional group chemistry are not fully clear at present. Strains of the genus Anabaena produce a broad range of $\mathrm{N}$-methylated microcystins (Fewer et al., 2007; Halinen et al., 2007; Harada et al., 1991; Krishnamurthy et al., 1989; Sivonen et al., 1992a, b). It has been shown in several studies that strains of the genus Anabaena produce mixtures of microcystins, some of which lack the $N$-methyl group (Halinen et al., 2007; Namikoshi et al., 1992a, b, 1998; Sivonen et al., 1992a, b). However, a number of Anabaena strains produce microcystins all of which lack the $N$-methyl group (Halinen et al., 2007; Namikoshi et al., 1992a, 1998; Sivonen et al., 1992a). Here we demonstrate that the exclusive production of microcystins lacking the $N$-methyl group in strains of Anabaena is associated with a natural in-frame deletion removing almost the entire NMT domain from $m c y A$.

\section{METHODS}

Culture preparation. We selected 26 microcystin-producing strains of the genus Anabaena from Denmark, Finland, Norway and the Baltic Sea (Table 1). To obtain sufficient biomass for LC-MS analysis the strains were grown under continuous white light at a photon irradiance of $7 \mu \mathrm{mol} \mathrm{m} \mathrm{m}^{-2} \mathrm{~s}^{-1}$ in $40 \mathrm{ml} \mathrm{Z8}$ medium lacking a source of combined nitrogen (Kotai, 1972). Cells were collected from 21day-old cultures by centrifugation at $7000 \mathrm{~g}$ for $7 \mathrm{~min}$ followed by the removal of excess medium. This step was repeated and the cells were stored at $-20{ }^{\circ} \mathrm{C}$.

\begin{abstract}
Assignment of microcystin structures. Cells were freeze-dried to aproximately 3-20 mg dry weight and homogenized with $0.5 \mathrm{~mm}$ diameter glass beads and $1 \mathrm{ml}$ 75/25 DMSO/acetonitrile. The mixture was shaken in a FastPrep FP120 cell disruptor (Savant Instruments) and then centrifuged at $10000 \mathrm{~g}$ for $3 \mathrm{~min}$. Whole-cell extracts were analysed by injecting $5 \mu \mathrm{l}$ of this extract into a Agilent 1100 series modular HPLC system (Agilent Technologies) equipped with a diode array detector and a mass spectrometer (Agilent XCT Plus Ion Trap). Whole-cell extracts were separated on a Luna C18(2) column $(2 \times 150 \mathrm{~mm}, 5 \mu \mathrm{m}$, Phenomenex) using the following linear mobile phase gradient: $10 \%(0 \mathrm{~min})$ to $50 \%(60 \mathrm{~min}) 2$-propanol in water $(+0.1 \% \mathrm{HCOOH})$ at a flow rate of $0.15 \mathrm{ml} \mathrm{min}^{-1}$ at $40{ }^{\circ} \mathrm{C}$.
\end{abstract}

Electrospray ionization was performed in positive-ion mode. Nebulizer gas $\left(\mathrm{N}_{2}\right)$ pressure was 30 p.s.i. $(207 \mathrm{kPa})$; drying gas flow and temperature were $81 \mathrm{~min}^{-1}$ and $350{ }^{\circ} \mathrm{C}$, respectively. The 
Table 1. Details of Anabaena strains studied

The strain number, geographical origin, year of isolation, NCBI accession number for the mcyA gene, presence or absence of the NMT domain in $m c y A$ and relative amounts $(\%)$ of amino acids present at the 7 th position of the microcystins produced by each strain are listed.

\begin{tabular}{|c|c|c|c|c|c|c|c|c|}
\hline Strain & Origin & Year & $m c y A$ & NMT & Mdha & MeSer $^{*}$ & Dha & Ser \\
\hline 1TU44S16 & Lake Tuusulanjärvi, Finland & 2001 & EU122309 & + & 100 & 0 & 0 & 0 \\
\hline 1TU46S11 & Lake Tuusulanjärvi, Finland & 2001 & EU122311 & + & 98 & $<1$ & $<1$ & $<1$ \\
\hline 0TU33S16 & Lake Tuusulanjärvi, Finland & 2000 & EU122312 & + & 96 & 1 & $<1$ & $<1$ \\
\hline 0TU43S7 & Lake Tuusulanjärvi, Finland & 2000 & EU122313 & + & 97 & 1 & $<1$ & $<1$ \\
\hline BIR 246 & Gulf of Finland, Baltic Sea & 2004 & EU122315 & + & 96 & 3 & 0 & 0 \\
\hline 1TU35S12 & Lake Tuusulanjärvi, Finland & 2001 & EU122316 & + & 98 & $<1$ & $<1$ & 0 \\
\hline 288 & Lake Littoistenjärvi, Finland & 1990 & EU122317 & + & 98 & 2 & 0 & 0 \\
\hline 0TU39S15b & Lake Tuusulanjärvi, Finland & 2000 & EU122318 & + & 97 & $<1$ & $<1$ & 0 \\
\hline 318 & Gulf of Finland, Baltic Sea & 1998 & EU122319 & + & 85 & 1 & 0 & 0 \\
\hline NIVA-CYA 83/1 & Lake Edlandsvatnet, Norway & 1981 & EU122320 & + & 99 & 0 & $<1$ & 0 \\
\hline 1TU30S4 & Lake Tuusulanjärvi, Finland & 2001 & EU122325 & - & 0 & 0 & 92 & 7 \\
\hline 1TU31S9 & Lake Tuusulanjärvi, Finland & 2001 & EU122326 & - & 0 & 0 & 88 & 5 \\
\hline $202 \mathrm{~A} 1 / 35$ & Lake Vesijärvi, Finland & 1987 & EU122327 & - & 0 & 0 & 94 & 3 \\
\hline PH256 & Lake Knud, Denmark & 1994 & EU122328 & - & 0 & 0 & 90 & 6 \\
\hline $202 \mathrm{~A} 2 / 41$ & Lake Vesijärvi, Finland & 1987 & EU122329 & - & 0 & 0 & 88 & 7 \\
\hline 1TU32S11 & Lake Tuusulanjärvi, Finland & 2001 & EU122330 & - & 0 & 0 & 92 & 6 \\
\hline 315 & Gulf of Finland, Baltic Sea & 1997 & EU122331 & - & 0 & 0 & 97 & 0 \\
\hline $66 \mathrm{~A}$ & Lake Kiikkara, Finland & 1986 & EU122332 & - & 0 & 0 & 91 & 7 \\
\hline $18 \mathrm{~B} 6$ & Lake Vaaranlampi, Finland & 1986 & EU122333 & - & 0 & 0 & 99 & 0 \\
\hline
\end{tabular}

${ }^{\star}$ MeSer-containing microcystins could not be assigned a complete structure, but MS ${ }^{2}$ fragmentation of the protonated molecular ions $m / z 999$ (Rt $39.5 \mathrm{~min}$ ) and $\mathrm{m} / \mathrm{z} 1013$ (Rt 40.3 and $41.9 \mathrm{~min}$ ) supported the presence of MeSer in position 7 in these microcystins.

capillary voltage was set to $5000 \mathrm{~V}$, capillary exit offset to $300 \mathrm{~V}$ and skimmer 1 potential to $85 \mathrm{~V}$ with a trap drive value of 144 . Spectra were recorded as averages of 4 using ultrascan mode and a scan range from 100 to $2200 \mathrm{~m} / z$. Tandem MS (MS ${ }^{2}$ ) spectra were recorded with auto MS mode with $1.0 \mathrm{~V}$ fragmentation amplitude. In auto MS mode a setting of 10 precursor ions was used with an isolation width of $4.0 \mathrm{~m} / \mathrm{z}$. The unusual $\beta$-amino acid Adda contains two conjugated $\pi$-bonds responsible for a UV absorbance maximum at $238 \mathrm{~nm}$, so the UV spectra of microcystins are characteristic. Microcystins were distinguished from other peptides based on the characteristic UV absorbance maximum at $238 \mathrm{~nm}$ as well as their mass spectral characteristics as $\mathrm{MH}^{+}$values corresponding to the range of published microcystins, loss of neutral fragment 134 in the ion source, occurrence of ions $m / z 599$ [(MeAsp)-Arg-Adda- $(\mathrm{Glu})+\mathrm{H}^{+}$] and $m / z$ 375/361 [Adda-134-Glu-(M)dha] in the $\mathrm{MS}^{2}$ spectrum. Structural identification of microcystin variants was based on interpretation of ions in $\mathrm{MS}^{2}$. MeSer-containing microcystins could not be assigned a complete structure, but $\mathrm{MS}^{2}$ fragmentation of the protonated molecular ions $\mathrm{m} / z 999$ (Rt $39.5 \mathrm{~min}$ ) and $\mathrm{m} / z 1013$ (Rt 40.3 and $41.9 \mathrm{~min}$ ) supported the presence of MeSer at position 7 in these microcystins.

DNA preparation. The whole-cell extracts used in LC-MS were evaporated to dryness with a vacuum pump. The dried cell matter was used for DNA extraction with the Qiagen DNeasy Plant Mini kit according to the manufacturer's instructions. The quality and quantity of DNA were measured on a UV spectrophotometer. Alternatively, cell lysates were prepared using an alkaline PEG lysis protocol (Chomczynski \& Rymaszewski, 2006).

PCR amplification and sequencing. We performed PCRs in a $20 \mu \mathrm{l}$ final volume containing approximately $20 \mathrm{ng}$ DNA, $1 \times$ DynaZyme II PCR buffer, $250 \mu \mathrm{M}$ of each deoxynucleotide, $0.5 \mu \mathrm{M}$ of each oligonucleotide primer, and 0.5 units of DynaZyme II DNA polymerase (Finnzymes). PCRs were also carried out using the BD Advantage Taq polymerase (BD Biosciences), $1 \times$ Advantage PCR buffer and otherwise the same conditions as above. The primer pair NMT-F (5'-CTCACAAATTCATTTCTCATTCCT-3')/NMT-R (5' GACGGATTTGTTCTAGAGATGGTAA-3') was used in PCR to amplify the $m c y A$ gene containing a portion of the C-terminal adenylation domain and the complete NMT domain with an expected size of $1682 \mathrm{bp}$. The following protocol was used: $95{ }^{\circ} \mathrm{C}$ for $3 \mathrm{~min} ; 30$ cycles of denaturation at $94{ }^{\circ} \mathrm{C}$ for $30 \mathrm{~s}$, annealing at $56{ }^{\circ} \mathrm{C}$ for $30 \mathrm{~s}$ and elongation at $72{ }^{\circ} \mathrm{C}$ for $2 \mathrm{~min}$; followed by a final elongation of $72{ }^{\circ} \mathrm{C}$ for $10 \mathrm{~min}$. The PCR products were purified using Montage PCR centrifugal filter devices (Millipore) or by the E.Z.N.A Gel Extraction kit (Omega Biotek). The purified PCR products were sequenced with the external primers NMT-F and NMT-R as well as the internal primers NMT-F2 (5'-CAGCGTCCAGCAGATAATTT$\left.3^{\prime}\right)$ and NMT-R2 (5'-TGAATATCATGGGGGACATC-3'). We 
amplified the mcyA gene from Nostoc sp. 152 using the NMT-F/NMT$\mathrm{R}$ primer pair using the same conditions as before but lowering the annealing temperature to $50{ }^{\circ} \mathrm{C}$. Sequencing was conducted under BigDye terminator cycling conditions, and sequencing reactions were purified using ethanol precipitation and separated on an Applied Biosystems 3730xl DNA analyser. Chromatograms were checked and edited with the CHROMAS 2.2 program (Technelysium). Contig assembly and alignment of the sequences were performed with the BIOEDIT sequence alignment editor.

Phylogenetic and structural analysis. The position of the NMT catalytic domain in peptide synthetases is highly conserved and located between the A8 and A9 core motifs of the adenylation domain (Marahiel et al., 1997). In order to characterize the deletion site in truncated mcyA gene sequences we aligned the McyA NMT and Nterminal adenylation domain amino acid sequences between the A8 and A9 conserved adenylation motifs against other adenylation domains, some of which contain this optional catalytic domain. We used conserved NMT domain motifs including the glycine-rich SAMbinding motif to guide the alignment (Marahiel et al., 1997; von Döhren et al., 1997).

In order to reconstruct the evolutionary history of the NMT domain we obtained and aligned a selection of NMT domain sequences from cyanobacteria, proteobacteria and chloroflexi. The set of NMT domains were identified in BLASTP searches using the NMT domain from Anabaena sp. 90 as a query (Rouhiainen et al., 2004). We included NMT domains involved in the biosynthesis of anabaenopeptilide, chondramide, tubulysin, myxochromides $S$ and barbamide as well as NMT domains identified in non-ribosomal peptide synthetases in the genomes of Herpetosiphon auranticus ATCC 23779, Nostoc punctiforme PCC73102, Anabaena variabilis ATCC 29413 and Nodularia spumigena CCY9414. We also included the NMT domain from the McyA protein in seven microcystin producers and the NdaA protein from two nodularin producers. We excluded missing and ambiguous regions and used 296 aa in phylogenetic analyses. Maximum-likelihood phylogenies were inferred using PROML implemented in the PHYLIP package (Felsenstein, 1993) with a JTT substitution model. Ten random additions with global rearrangements were used to find the optimal tree. We performed 1000 bootstrap replicates with the SEQBOOT, PROTDIST, NEIGHBOR and CONSENSE programs and using the JTT substitution model in the PHYLIP package (Felsenstein, 1993). Phylogenetic trees were rooted with the NMT domain from a mixed polyketide synthetase-nonribosomal peptide synthetase protein from the genome of Myxococcus xanthus DK 1622.

\section{RESULTS}

We identified strains of Anabaena carrying truncated $m c y A$ genes via PCR with primers specific for regions of the $m c y A$ adenylation domain flanking the NMT domain (Fig. 2). By sequence analysis we characterized a $1236 \mathrm{bp}$ in-frame deletion in the $m c y A$ gene in strains of Anabaena isolated from Denmark, Finland and the Baltic Sea (Table 1). Of the 26 strains included in this study, nine contained the 1236 bp deletion (Fig. 2, Table 1). In all cases the deletion occurred at the same position of the $m c y A$ gene, removing 410 aa of the NMT catalytic domain from McyA. The deletion removed almost the entire NMT domain and two amino acids of the adenylation domain between amino acid positions 730 and 1130 of full-length McyA (CAD60101). Comparison with other cyanobacterial adenylation domains suggests that only a short 13 aa remnant of

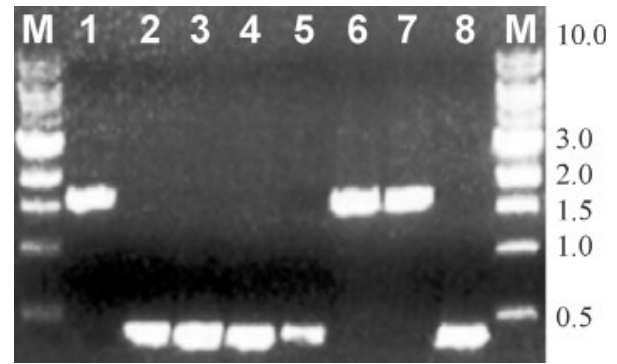

Fig. 2. A $1.5 \%$ agarose gel illustrating the truncated (lanes 2-5, 8) and full-length (lanes 1, 6-7) mcyA PCR products from a selection of Anabaena strains: 1, 1TU44S16; 2, 1TU30S4; 3, 1TU31S9; 4, 202A1/35; 5, PH256; 6, 1TU44S9; 7, 1TU46S11; 8, 202A2/41. M, 1 kb DNA ladder (New England Biolabs).

the NMT domain was retained after the deletion event (Fig. 3). Anabaena strains isolated in different years from a number of different lakes in Denmark and Finland, as well as from the Baltic Sea, carried the in-frame deletion mutation in the mcyA gene (Table 1).

The 26 strains of Anabaena included in this study produced a broad range of microcystins (see supplementary Table S1, available with the online version of this paper). We identified between 2 and 14 microcystins in each strain and the dominant variant in most strains was MC-LR, [DAsp $\left.{ }^{3}\right] \mathrm{MC}-\mathrm{LR}$ or $\left[\mathrm{Dha}^{7}\right] \mathrm{MC}-\mathrm{LR}$ (Table S1). We observed variation in the type of amino acid incorporated at the $\mathrm{X}$ position (Table S1). Most strains produced microcystins containing L-leucine but some strains produced microcystins containing $\mathrm{L}$-arginine at the $\mathrm{X}$ position and in trace amounts L-homoisoleucine, L-homotyrosine, L-phenylalanine or L-homophenylalanine at the X position (Table S1). A series of microcystins were identified in 17 strains of Anabaena, $85-100 \%$ of which contained Mdha (Fig. 4).

I $\quad$\begin{tabular}{llllllll}
$\mathrm{A} 8$ & 1 & $\mathrm{M} 1,2$ & 3 & 4 & $\mathrm{M} 2,5$ & $\mathrm{M} 3,6$ & $\mathrm{~A} 9$ \\
\hline & & & & & & &
\end{tabular}

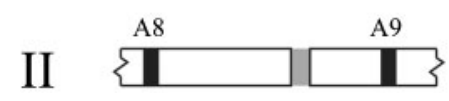

Fig. 3. Schematic illustrating the in-frame deletion mutation in strains of the genus Anabaena. The alignment includes the adenylation domains from the conserved core motifs A8-A9 and the NMT domain core motifs M1-M3 (Marahiel et al., 1997) and conserved NMT domain core motifs 1-6 (von Döhren et al., 1997). Anabaena strains carrying full-length mcyA genes (I): 90, 1TU44S16, 1TU44S9, 1TU46S11, 0TU33S16, OTU43S7, 258, BIR246, 1TU35S12, 288, 0TU39S15b, 318, NIVA 83/1, NIVA 267/ 4, NIVA 269/2, NIVA 269/6, NIVA 270/1 and 1TU4436. Anabaena strains carrying truncated mcyA genes (II): PH256, 1TU30S4, 1TU31S9, 202A1/35, 202A2/41, 1TU32S11, 66A, 315 and $18 \mathrm{~B} 6$. 


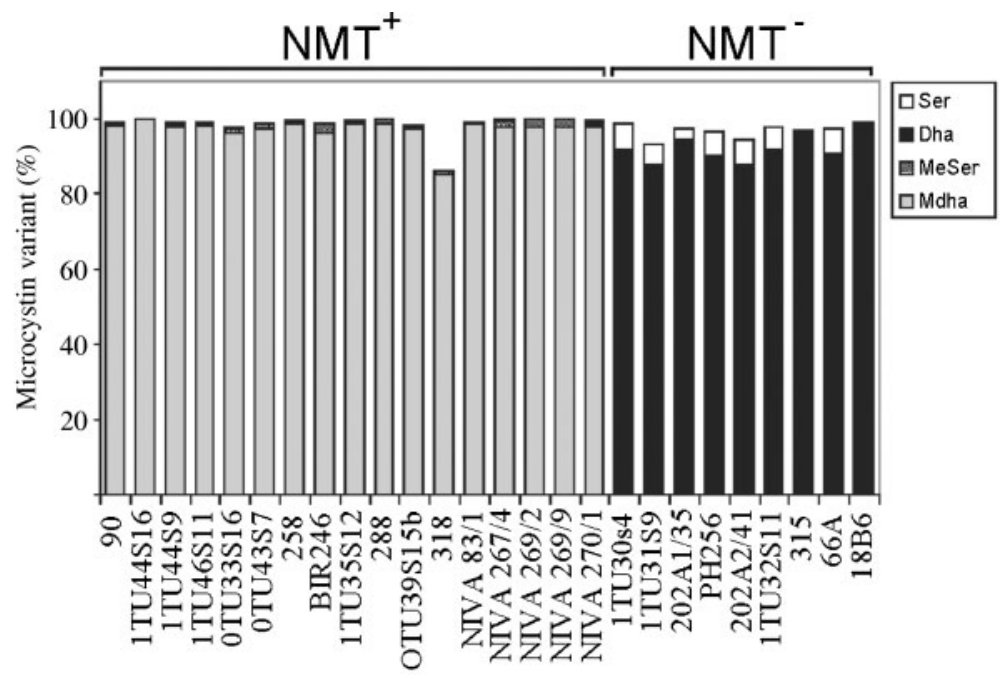

Fig. 4. Relative percentage of amino acids located at the 7th position of the microcystin variants which could be assigned a structure produced by the 26 strains of Anabaena included in this study. Some variants produced by these strains could not be assigned a structure. Some strains produced microcystins containing Dha or MeSer in trace amounts (see Table 1). The presence $\left(\mathrm{NMT}^{+}\right)$or absence $\left(\mathrm{NMT}^{-}\right)$of the NMT domain in $m c y A$ is associated with the incoporation of Mdha and Dha respectively.

However, a subset of these strains also produced trace amounts (0.1-1.4\%) of microcystins containing Dha (Fig. 4, Table 1). The remaining 9 strains produced microcystins $88-100 \%$ of which contained Dha at the seventh position (Fig. 4). Interestingly, 3-7\% of the microcystins produced by 7 of these 9 strains contained L-Ser instead of Mdha (Fig. 4). Anabaena sp. 18B6 and 315 produced microcystins which only contained Dha (Fig. 4). Microcystins containing L-Ser were present only in trace amounts in strains producing $N$-methylated microcystins (Table 1). Low amounts of microcystins containing LMeSer could be identified in some strains (Table 1).
Phylogenetic analyses demonstrated that NMT domains from McyA form a monophyletic group (Fig. 5). We observed a primary split with Planktothrix and Microcystis and the heterocyst-forming strains Anabaena and Nostoc grouping separately (Fig. 5). We did not find support for the monophyly of nodularin and microcystin synthetase NMT domains (Fig. 5). The topology may suggest that these catalytic domains cluster in separate parts of the maximum-likelihood tree (Fig. 5). However, all but the terminal branches in the tree are unresolved, and a sister group relationship between nodularin and microcystin NMTs cannot be ruled out.

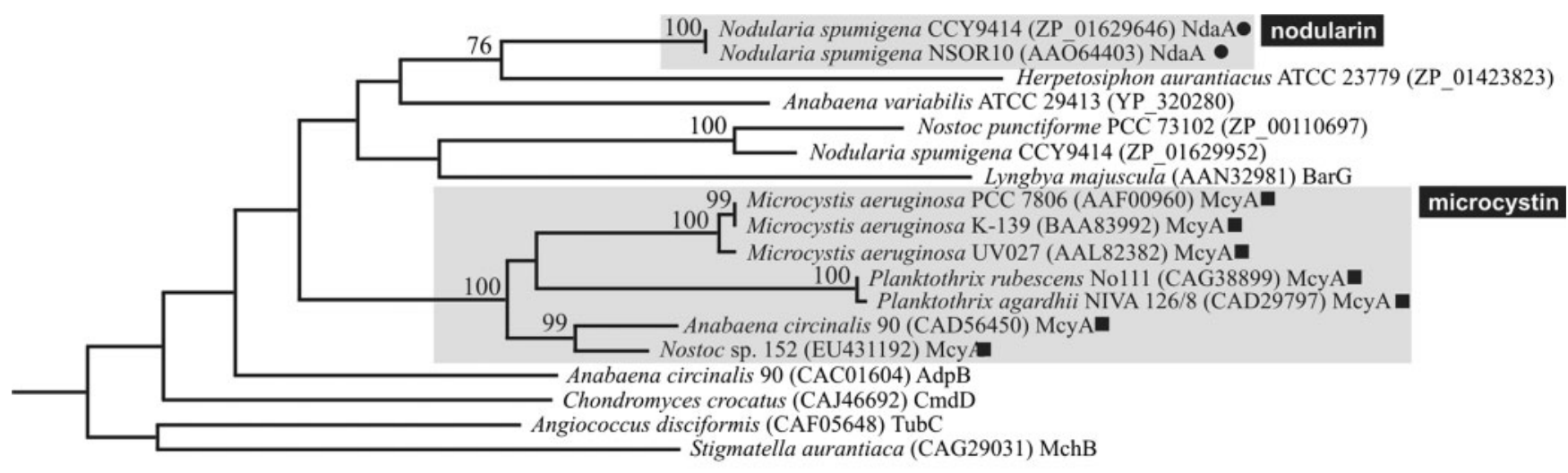

10

Fig. 5. Phylogenetic relations between NMT domains from McyA in the microcystin synthetase gene cluster and NdaA in the nodularin synthetase gene cluster, as well as NMT domains from a variety of homologous non-ribosomal peptide synthetases (see text for details). The NMT domains involved in the biosynthesis of Mdhb are denoted with $\bullet$ and the NMT domains involved in the biosynthesis of Mdha are denoted with $\mathbf{\square}$; they group separately. A maximum-likelihood tree (In likelihood $=-7295.07475$ ) with bootstrap values above $50 \%$ shown at the nodes. Branch lengths are proportional to sequence change. 


\section{DISCUSSION}

Microcystins are synthesized on large multienzyme complexes consisting of polyketide synthases and non-ribosomal peptide synthetases in Anabaena (Rouhiainen et al., 2004). Nearly all of the 48 catalytic reactions necessary for the biosynthesis of microcystin can be assigned to the 10 proteins encoded in this $55 \mathrm{~kb}$ gene cluster (Rouhiainen et al., 2004). The range of variation of microcystins produced by the strains of Anabaena included in this study is consistent with previous observations (Fewer et al., 2007; Halinen et al., 2007; Namikoshi et al., 1992a, b, 1998; Sivonen et al., 1992a, b). The 425 aa NMT domain of McyA is responsible for the $N$-methylation of the microcystin and is inserted between the core motifs A8 and A9 of the first adenylation domain in $m c y A$ in Anabaena 90 (Rouhiainen et al., 2004). Here we identified an association between the incoporation of Dha into microcystins and the deletion of the NMT domain in $35 \%$ of the strains examined (Fig. 4). The 412 aa in-frame deletion removes almost the entire NMT domain and 2 aa of the adenylation domain, leaving only a small 11 aa NMT remnant (Fig. 3). All conserved NMT domain motifs (Marahiel et al., 1997; von Döhren et al., 1997) were absent in the deletion mutants, including the glycine-rich SAM-binding motif (Marahiel et al., 1997).

The sequence similarity between the regions flanking the deletion site in the 26 strains of Anabaena is between 98 and $100 \%$ (data not shown). The regions of $m c y A$ genes flanking the deletion site differ from other $m c y A$ genes by just three basepairs (data not shown). It is not clear how the in-frame deletion took place. Possible mechanistic explanations for the deletion event could be rare homologous, homeologous, or illegitimate repair of doublestrand breaks in the NMT domain following DNA damage resulting in an in-frame fusion. Such a model would not invoke co-conversion of the adenylation domain through a homologous recombination event. Strains of cyanobacteria producing microcystin variants containing either Dha or Dhb exclusively are known from all major producers of microcystins (Sivonen \& Jones, 1999). This suggests that in addition to Anabaena and Planktothrix some strains of Microcystis and Nostoc either contain inactive NMT domains or lack the domain completely. Microcystins containing Dhb in Planktothrix are thought to be the result of a homologous recombination event in the first module of $m c y A$ which replaces the adenylation domain, leading to the change in substrate specificity and presumably the concomitant deletion of the NMT domain (Kurmayer et al., 2005). Our results suggest a parallel but independent strategy for producing microcystins lacking the $N$-methyl group in Anabaena through deletion of the NMT domain alone without co-conversion of the adenylation domain.

The N-terminal adenylation domain of McyA recognizes and activates L-Ser as an AMP-adenylate (Christiansen et al., 2003; Nishizawa et al., 1999; Rouhiainen et al., 2004; Tillett et al., 2000). The Ser residue undergoes $N$ methylation and dehydration to form Mdha
(Christiansen et al., 2003; Nishizawa et al., 1999; Rouhiainen et al., 2004; Tillett et al., 2000). The order and timing of the $N$-methylation, dehydration and condensation reactions are not clear at present. Interestingly there is a 10-500-fold increase in the amount of L-Ser incorporated into the microcystins in the strains of Anabaena lacking a functional NMT domain (Table 1). This suggests that there may be a functional coupling of the dehydration and $N$-methylation reactions. Additional expression studies, enzyme characterization and kinetic experiments are required to unravel the order and timing of these catalytic reactions in the biosynthesis of Mdha.

The majority of strains in this study produce microcystins containing Mdha (Fig. 4). However, all strains produced mixtures of microcystins and we identified trace amounts of microcystins containing Dha in some strains even in the presence of a functional NMT domain (Fig. 4). A fundamental feature of modular non-ribosomal peptide synthetases is the highly predictable relationship between the domain order and the chemical functional groups of resultant non-ribosomal peptide products (Marahiel et al., 1997). The simultaneous production of Mdha- and Dhacontaining microcystins in Anabaena could be the result of the inaction of the NMT domain during the assembly of Dha-containing microcystins. However, the concomitant biosynthesis of Dha- and Mdha-containing microcystin variants could also be the result of a limitation of the SAM precursor of the methyl group (Marahiel et al., 1997). Such mixtures of microcystins containing both Mdha and Dha are common in Planktothrix (Luukkainen et al., 1993) and Microcystis (Robillot et al., 2000), and inaction of the NMT domain may be a widespread feature of microcystin biosynthesis.

The cyclic pentapeptide nodularin and the cyclic heptapeptide microcystin share a similar chemical structure (Sivonen \& Jones, 1999) and nodularin synthetase is believed to have evolved from a microcystin synthetase progenitor (Moffitt \& Neilan, 2004; Rantala et al., 2004). The nodularin synthetase gene cluster is proposed to have arisen following deletion of two non-ribosomal peptide synthetase modules and a change in substrate specificity from L-Ser to L-Thr in the C-terminal adenylation domain of $\mathrm{NdaA}$ (Moffitt \& Neilan, 2004). Interestingly, we find that the NMT domains from microcystin and nodularin synthetase proteins McyA and NdaA do not have the same topology as other regions of the mcy and nda gene clusters (Fig. 5) as might be expected in an evolutionary scenario where all nodularin and microcystin synthetase genes share the same evolutionary history (Rantala et al., 2004). There is no decisive evidence for a sister taxa relationship between the two domains (Fig. 5). Instead, the phylogenetic position of the NdaA NMT domains suggests that the proposed change in substrate specificity in the nodularin synthetase gene cluster from Mdha to Mdhb (Moffitt \& Neilan, 2004; Rantala et al., 2004) may have been the result of a recombination event resulting in the replacement of both the $\mathrm{N}$-terminal adenylation domain and the NMT domain in ndaA. 
Many important antibiotics, antimicrobial compounds, siderophores and toxins are synthesized on non-ribosomal peptide synthetase enzyme complexes (Marahiel et al., 1997; von Döhren et al., 1997). The modular structure of non-ribosomal peptide synthetases allows the rational design of novel peptides by targeted replacement of these catalytic domains (Stachelhaus et al., 1995). There is much current interest in engineering non-ribosomal peptide synthetases in order to create new peptides with potential biological activities (Sieber \& Marahiel, 2005). Understanding the natural evolution of non-ribosomal biosynthetic pathways can provide insights useful in developing combinatorial engineering strategies and rational design of novel metabolites and pharmaceuticals. Our results demonstrate that it is possible to create functional non-ribosomal peptide synthetases through partial in-frame deletion of the NMT domain, and the deletion site identified here may prove useful in defining potential deletion strategies. This study further demonstrates in one of the few natural examples that the deletion of biosynthetic domains can lead to new biosynthetic outcomes. This naturally occurring mechanism is an important addition to the known evolutionary strategies for generating structural diversity in nonribosomal peptides such as module (Kurmayer et al., 2005) or domain replacement (Fewer et al., 2007; Mikalsen et al., 2003).

\section{ACKNOWLEDGEMENTS}

This work was supported by grants from the European Union PEPCY (QLK4-CT-2002-02634) and the Academy of Finland to D.P.F. (1212943) and K.S. (53305 and 214457). We thank Dr Peter Hendriksen for providing us with the Anabaena sp. PH256 culture, and Lyudmila Saari for her valuable help in handling the cultures.

\section{REFERENCES}

Carmichael, W. W. (1994). The toxins of cyanobacteria. Sci Am 270, 78-86.

Chomczynski, P. \& Rymaszewski, M. (2006). Alkaline polyethylene glycol-based method for direct PCR from bacteria, eukaryotic tissue samples, and whole blood. Biotechniques 40, 454-458.

Christiansen, G., Fastner, J., Erhard, M., Börner, T. \& Dittmann, E. (2003). Microcystin biosynthesis in Planktothrix: genes, evolution, and manipulation. J Bacteriol 185, 564-572.

Dittmann, E., Neilan, B. A., Erhard, M., von Döhren, H. \& Börner, T. (1997). Insertional mutagenesis of a peptide synthetase gene that is responsible for hepatotoxin production in the cyanobacterium Microcystis aeruginosa PCC 7806. Mol Microbiol 26, 779-787.

Felsenstein, J. (1993). PHYLIP (phylogeny inference package), version 3.5. Distributed by the author. Department of Genome Sciences, University of Washington, Seattle, USA.

Fewer, D. P., Rouhiainen, L., Jokela, J., Wahlsten, M., Laakso, K., Wang, H. \& Sivonen, K. (2007). Recurrent adenylation domain replacement in the microcystin synthetase gene cluster. BMC Evol Biol $7,183$.

Finking, R. \& Marahiel, M. A. (2004). Biosynthesis of nonribosomal peptides. Annu Rev Microbiol 58, 453-488.
Halinen, K., Jokela, J., Fewer, D. P., Wahlsten, M. \& Sivonen, K. (2007). Direct evidence for production of microcystins by Anabaena strains from the Baltic Sea. Appl Environ Microbiol 73, 6543-6550.

Harada, K.-I., Ogawa, K., Kimura, Y., Murata, H., Suzuki, M., Thorn, P. M., Evans, W. R. \& Carmichael, W. W. (1991). Microcystins from Anabaena flos-aquae NRC 525-17. Chem Res Toxicol 4, 535-540.

Jochimsen, E. M., Carmichael, W. W., An, J. S., Cardo, D. M., Cookson, S. T., Holmes, C. E., Antunes, M. B., de Melo Filho, D. A., Lyra, T. M. \& other authors (1998). Liver failure and death after exposure to microcystins at a hemodialysis center in Brazil. $N$ Engl J Med 338, 873-878.

Kahru, M. (1997). Using satellites to monitor large-scale environmental change in the Baltic Sea. In Monitoring Algal Blooms: New Techniques for Detecting Large-Scale Environmental Change, pp. 43-61. Edited by M. Kahru \& C. W. Brown. Berlin, Germany: Springer-Verlag.

Karlsson, K. M., Kankaanpää, H., Huttunen, M. \& Meriluoto, J. (2005). First observation of microcystin-LR in pelagic cyanobacterial blooms in the northern Baltic Sea. Harmful Algae 4, 163-166.

Kotai, J. (1972). Instructions for Preparation of Modified Nutrient Solution Z8 for Algae. Norwegian Institute for Water Research Publication B-11/69. Oslo: Norwegian Institute for Water Research.

Krishnamurthy, T., Szafraniec, L., Hunt, D. F., Shabanowitz, J., Yates, J. R., III, Hauer, C. R., Carmichael, W. W., Skulberg, O., Codd, G. A. \& Missler, S. (1989). Structural characterization of toxic cyclic peptides from blue-green algae by tandem mass spectrometry. Proc Natl Acad Sci U S A 86, 770-774.

Kurmayer, R., Christiansen, G., Gumpenberger, M. \& Fastner, J. (2005). Genetic identification of microcystin ecotypes in toxic cyanobacteria of the genus Planktothrix. Microbiology 151, 1525-1533.

Lautru, S. \& Challis, G. L. (2004). Substrate recognition by nonribosomal peptide synthetase multi-enzymes. Microbiology 150, 1629-1636.

Luukkainen, R., Sivonen, K., Namikoshi, M., Färdig, M., Rinehart, K. L. \& Niemelä, S. I. (1993). Isolation and identification of eight microcystins from thirteen Oscillatoria agardhii strains and structure of a new microcystin. Appl Environ Microbiol 59, 2204-2220.

MacKintosh, C., Beattie, K. A., Klumpp, S., Cohen, P. \& Codd, G. A. (1990). Cyanobacterial microcystin-LR is a potent and specific inhibitor of protein phosphatases 1 and $2 \mathrm{~A}$ from both mammals and higher plants. FEBS Lett 264, 187-192.

Marahiel, M. A., Stachelhaus, T. \& Mootz, H. D. (1997). Modular peptide synthetases involved in nonribosomal peptide synthesis. Chem Rev 97, 2651-2674.

Mikalsen, B., Boison, G., Skulberg, O. M., Fastner, J., Davies, W., Gabrielsen, T. M., Rudi, K. \& Jakobsen, K. S. (2003). Natural variation in the microcystin synthetase operon mcyABC and impact on microcystin production in Microcystis strains. J Bacteriol 185, 2774-2785.

Moffitt, M. C. \& Neilan, B. A. (2004). Characterization of the nodularin synthetase gene cluster and proposed theory of the evolution of cyanobacterial hepatotoxins. Appl Environ Microbiol 70, 6353-6362.

Namikoshi, M., Sivonen, K., Evans, W. R., Carmichael, W. W., Sun, F., Rouhiainen, L., Luukkainen, R. \& Rinehart, K. L. (1992a). Two new Lserine variants of microcystins-LR and -RR from Anabaena sp. strains 202 A1 and 202 A2. Toxicon 30, 1457-1464.

Namikoshi, M., Sivonen, K., Evans, W. R., Carmichael, W. W., Rouhiainen, L., Luukkainen, R. \& Rinehart, K. L. (1992b). Structures of three new homotyrosine-containing microcystins and a new homophenylalanine variant from Anabaena sp. strain 66. Chem Res Toxicol 5, 661-666.

Namikoshi, M., Yuan, M., Sivonen, K., Carmichael, W. W., Rinehart, K. L., Rouhiainen, L., Sun, F., Brittain, S. \& Otsuki, A. (1998). Seven 
new microcystins possessing two L-glutamic acid units, isolated from Anabaena sp. strain 186. Chem Res Toxicol 11, 143-149.

Nishiwaki-Matsushima, R., Ohta, T., Nishiwaki, S., Suganuma, M., Kohyama, K., Ishikawa, T., Carmichael, W. W. \& Fujiki, H. (1992). Liver tumor promotion by the cyanobacterial cyclic peptide toxin microcystin-LR. J Cancer Res Clin Oncol 118, 420-424.

Nishizawa, T., Asayama, M., Fujii, K., Harada, K. \& Shirai, M. (1999). Genetic analysis of the peptide synthetase genes for a cyclic heptapeptide microcystin in Microcystis spp. J Biochem (Tokyo) 126, 520-529.

Rantala, A., Fewer, D. P., Hisbergues, M., Rouhiainen, L., Vaitomaa, J., Börner, T. \& Sivonen, K. (2004). Phylogenetic evidence for the early evolution of microcystin synthesis. Proc Natl Acad Sci U S A 101, 568-573.

Ressom, R., Soong, F. S., Fitzgerald, J., Turczynowicz, L., El Saadi, O., Roder, D., Maynard, T. \& Falconer, I. R. (1994). Health Effects of Toxic Cyanobacteria (Blue-Green Algae). Canberra: National Health and Medical Council, Australian Government Publishing Service.

Robillot, C., Vinh, J., Puiseux-Dao, S. \& Hennion, M. C. (2000). Hepatotoxin production kinetics of the cyanobacterium Microcystis aeruginosa PCC 7820, as determined by HPLC: mass spectrometry and protein phosphatase bioassay. Environ Sci Technol 34, 3372-3378.

Rouhiainen, L., Vakkilainen, T., Siemer, B. L., Buikema, W., Haselkorn, R. \& Sivonen, K. (2004). Genes coding for hepatotoxic heptapeptides (microcystins) in the cyanobacterium Anabaena strain 90. Appl Environ Microbiol 70, 686-692.

Sieber, S. A. \& Marahiel, M. A. (2005). Molecular mechanisms underlying non-ribosomal peptide synthesis: approaches to new antibiotics. Chem Rev 105, 715-738.
Sivonen, K. \& Jones, G. (1999). Cyanobacterial toxins. In Toxic Cyanobacteria in Water, pp. 41-111. Edited by I. Chorus \& J. Bartram. London: E\&FN Spon.

Sivonen, K., Namikoshi, M., Evans, W. R., Carmichael, W. W., Sun, F., Rouhiainen, L., Luukkainen, R. \& Rinehart, K. L. (1992a). Isolation and characterization of a variety of microcystins from seven strains of the cyanobacterial genus Anabaena. Appl Environ Microbiol 58, 2495-2500.

Sivonen, K., Skulberg, O. M., Namikoshi, M., Evans, W. R., Carmichael, W. W. \& Rinehart, K. L. (1992b). Two methyl ester derivatives of microcystins, cyclic heptapeptide hepatotoxins, isolated from Anabaena flos-aquae strain CYA 83/1. Toxicon 30, 1465-1471.

Stachelhaus, T., Schneider, A. \& Marahiel, M. A. (1995). Rational design of peptide antibiotics by targeted replacement of bacterial and fungal domains. Science 269, 69-72.

Stal, L. J., Albertano, P., Bergman, B., von Bröckel, K., Gallon, J. R., Hayes, P. K., Sivonen, K. \& Walsby, A. E. (2003). BASIC: Baltic Sea cyanobacteria: an investigation of the structure and dynamics of water blooms of cyanobacteria in the Baltic Sea - responses to a changing environment. Cont Shelf Res 23, 1695-1714.

Tillett, D., Dittmann, E., Erhard, M., von Döhren, H., Börner, T. \& Neilan, B. A. (2000). Structural organization of microcystin biosynthesis in Microcystis aeruginosa PCC 7806: an integrated peptide-polyketide synthetase system. Chem Biol 7, 753-764.

von Döhren, H., Keller, U., Vater, J. \& Zocher, R. (1997). Multifunctional peptide synthetases. Chem Rev 97, 2675-2705.

WHO (1998). Guidelines for Drinking Water Quality: Addendum to Volume 2, Health Criteria and Other Supporting Information, 2nd edn, pp. 1-283. Geneva: World Health Organization.

Edited by: D. J. Scanlan 